\title{
Congruent Genetic Structure in the Lichen-Forming Fungus Lobaria pulmonaria and Its Green-Algal Photobiont
}

\author{
Silke Werth and Christoph Scheidegger \\ Swiss Federal Research Institute WSL, Zürcherstrasse 111, CH-8903 Birmensdorf, Switzerland
}

Submitted 31 March 2011. Accepted 26 October 2011.

\begin{abstract}
The extent of codispersal of symbionts is one of the key factors shaping genetic structures of symbiotic organisms. Concordant patterns of genetic structure are expected in vertically transmitted symbioses, whereas horizontal transmission generally uncouples genetic structures unless the partners are coadapted. Here, we compared the genetic structures of mutualists, the lichen-forming fungus Lobaria pulmonaria and its primary green-algal photobiont, Dictyochloropsis reticulata. We performed analysis of molecular variance and variogram analysis to compare genetic structures between symbiosis partners. We simulated the expected number of multilocus-genotype recurrences to reveal whether the distribution of multilocus genotypes of either species was concordant with panmixia. Simulations and tests of linkage disequilibrium provided compelling evidence for the codispersal of mutualists. To test whether genotype associations between symbionts were consistent with randomness, as expected under horizontal transmission, we simulated the recurrence of fungal-algal multilocus genotype associations expected by chance. Our data showed nonrandom associations of fungal and algal genotypes. Either vertical transmission or horizontal transmission coupled with coadaptation between symbiont genotypes may have created these nonrandom associations. This study is among the first to show codispersal and highly congruent genetic structures in the partners of a lichen mutualism.
\end{abstract}

The mode of symbiont transmission to the next generation and the extent of codispersal are key factors shaping the genetic structures of symbiotic organisms (Wade 2007). Strictly vertical transmission leads to similar genetic structures in the symbionts (Bongaerts et al. 2010; Werth and Sork 2010). Horizontal transmission mode generally uncouples genetic structures of symbionts (Jones et al. 2006; Mulvey et al. 1991; Werth and Sork 2010), unless hosts exhibit high specificity for specific (e.g., locally adapted) symbionts (Parker and Spoerke 1998). However, asymmetries in gene flow between symbiotic partners also may cause differential genetic structures in vertically transmitted symbioses (Sullivan and Faeth 2004).

Congruence in patterns of gene movement promotes coevolutionary processes (Anderson et al. 2004). Because the out-

Corresponding author: Telephone: +41 4473921 11; Fax: +41 4473922 15; S. Werth; E-mail: silke.werth@wsl.ch

* The $e$-Xtra logo stands for "electronic extra" and indicates that three supplementary tables are published online. come of selection acting on a population of one species in a particular environmental setting may depend on the standing genetic variation in a population of an interacting species (Wade 2003), it is essential to study co-evolutionary patterns, including symbiont transmission mode, at the level of genes and genotypes (Wade 2007).

In lichen symbiosis, a symbiotic association between a fungus and one or several photosynthetic partners (green-algal or cyanobacterial "photobionts") (Büdel and Scheidegger 2008), both vertical and horizontal transmission of photobionts to the next generation of mycobionts may occur. In clonally reproducing lichens, the dispersed clonal propagules carry photobiont cells of the "mother" thallus. Vertical transmission of the photobiont occurs if photobionts are recruited from these codispersed cells. In the case of horizontal transmission, photobionts are switched either during the juvenile development of thalli from fungal ascospores or when photobionts are recruited from free-living algal populations or other soredia during the establishment of thalli from clonal propagules (Wornik and Grube 2010).

The comparison of genetic structures between mycobiont and photobiont populations offers valuable insight into gene flow patterns in the symbionts. In vertically transmitted systems, a high degree of correspondence of genetic patterns between mycobionts and photobionts is expected due to the codispersal of both symbiotic partners, as opposed to horizontally transmitted symbioses, where no such correspondence is expected (Werth and Sork 2010). If photobionts possess dispersal capability on their own and are incorporated from freeliving populations, gene flow patterns are expected to be skewed, leading to dissimilar genetic structures.

The expected degree of concordance in genetic structures between symbionts also depends on the specificity (taxonomic range) and selectivity (frequency of association with particular photobiont taxa) of the mycobiont species (Rambold et al. 1998; Yahr et al. 2004). Many if not most mycobionts are highly specific at the level of species or strains of photobionts (Beck et al. 1998, 2002; Piercey-Normore 2009). If there is coadaptation between symbiosis partners (e.g., reciprocal adaptation for specific partner genotypes), photobiont switches may not lead to an entirely random association but will shuffle the compatible photobionts between mycobionts of the next generation. In this case, the genetic structures of the symbiosis partners could be concordant even if photobionts are switched during establishment, because coadaptation would create nonrandom associations between fungal and algal genotypes. One emerging pattern from population genetic studies is that photobiont and mycobiont populations often exhibit markedly different genetic structures, which implies the predominance of 
horizontal transmission of the photobiont and a lack of coadaptation between symbionts (Piercey-Normore 2006; Werth and Sork 2008, 2010; Wornik and Grube 2010; Yahr et al. 2006). Only one study at the range-wide scale has reported partially congruent genetic structures in mycobionts and photobionts, and has emphasized the importance of symbiont codispersal (Fernández-Mendoza et al. 2011).

The reproductive mode of the mycobiont may impact the genetic architecture of the symbiosis markedly. The relative importance of sexual versus clonal reproductive mode can be inferred by comparing the observed distribution of multilocus genotypes (MLG) with the expectation under random mating. Clonal reproduction reduces the number of MLG and increases the frequency of recurrent MLG (i.e., the number of times an MLG is expected to be observed more than once) (Werth and Sork 2008).

The difference between observed and expected frequencies of association in the symbiont genotypes reveals whether fungal-algal genotype associations are consistent with randomness, as expected under repeated horizontal transmission of photobiont partners. Vertical transmission reduces the number of associated photobiont MLG and increases the frequency of mycobiont genotypes associating with one or few photobiont genotypes. Second, if a symbiosis were strictly vertically transmitted, assignment tests should reveal congruent assignments of mycobiont and photobiont individuals to the same gene pools, whereas photobiont switches should lead to discrepancies in assignments between symbionts.

Here, we study Lobaria pulmonaria L. (Hoffm.), a charismatic epiphytic lichen that has faced a severe decline in Central Europe due to air pollution and habitat destruction. The primary photobiont of L. pulmonaria is the green-alga Dictyochloropsis reticulata (Tschermak-Woess) Tschermak-Woess (Tschermak-Woess 1995). Our present analysis is based upon a landscape-level population dataset of Werth and associates (2006b, 2007), which we analyze separately for fungal and algal microsatellite markers sensu Widmer and associates (2010), adding seven algal and five fungal microsatellites to increase marker resolution. We were mainly interested in possible differences in the genetic structure between L. pulmonaria and its photobiont and in finding out whether the symbiosis partners were codispersed, rather than in performing a detailed analysis of both partners with respect to historic disturbance, which had been studied in detail by Werth and associates (2006b). In Switzerland, L. pulmonaria has been suggested to reproduce mainly clonally through wind-dispersed soredia (Werth et al. 2006a; Scheidegger and Werth 2009). Fertile, apothecia-bearing thalli are found in low frequency in Swiss populations of $L$. pulmonaria but the relative importance of sexual versus clonal reproduction remains unknown.

Table 1. Hierarchical analysis of molecular variance (AMOVA), showing the mean $\Phi$-statistics for eight fungal loci of Lobaria pulmonaria, and 10 loci of its green-algal photobiont Dictyochloropsis reticulata ${ }^{\mathrm{a}}$

\begin{tabular}{lcc}
\hline Source of variance & Mycobiont & Photobiont \\
\hline Tree level & & \\
Between plots $\left(\Phi_{\mathrm{CT}}\right)$ & $0.399^{*}$ & $0.345^{*}$ \\
Between host trees within plots $\left(\Phi_{\mathrm{SC}}\right)$ & $0.785^{*}$ & $0.785^{*}$ \\
Overall $\Phi_{\mathrm{ST}}$ & $0.871^{*}$ & $0.859^{*}$ \\
Plot level & & \\
Between regions $\left(\Phi_{\mathrm{CT}}\right)$ & $-0.008^{\mathrm{ns}}$ & $-0.014^{\mathrm{ns}}$ \\
Between plots within regions $\left(\Phi_{\mathrm{SC}}\right)$ & $0.526^{*}$ & $0.483^{*}$ \\
Overall $\Phi_{\mathrm{ST}}$ & $0.523^{*}$ & $0.476^{*}$ \\
\hline
\end{tabular}

${ }^{a}$ In the two-way AMOVAs, trees were nested within 1-ha plots in the treelevel analysis and plots were nested within regions at the plot level. An asterisk indicates that the respective variance component is statistically significant $(P<0.05) ; \mathrm{ns}=$ not significant.
Here, we compare the spatial genetic structures of L. pulmonaria and its photobiont using a combination of spatial autocorrelation analyses, analyses of genetic structure, and analyses of the association between photobiont and mycobiont genotypes. One of the aims of our study was to infer the reproductive mode of the lichen fungus and its photobiont, and to assess whether the photobiont was codispersed with the mycobiont. Our main question was whether there was evidence for codispersal and coadaptation of the symbiosis partners.

\section{RESULTS}

\section{Population structure.}

Results from analysis of molecular variance (AMOVA) indicated that, in both taxa, there was no significant genetic differentiation between groups of populations from the spatially segregated western and eastern parts of the study area ("regions"). In contrast, significant differentiation was observed between samples collected from different 1-ha plots and trees (Table 1). The genetic structures of mycobionts and photobionts as measured with AMOVA were highly similar at the tree and plot level.

\section{Linkage disequilibrium.}

Consistent with a strong signal of clonality in our data, we found significant linkage disequilibrium between all fungal and algal loci. In addition, significant linkage was found in 67 of 70 comparisons between fungal and algal loci (Supplementary Table S1). Also, at the level of sampling plots, significant linkage disequilibrium was found (Fig. 1). In most plots, a high number of markers was linked in the photobiont and the mycobiont and among partners. The fungus showed the strongest signal of linkage disequilibrium, with significant disequilibria in most plots in the east and south of the study area. Interestingly, in two plots in the northern part of the study area, none of the markers were linked, pointing toward fungal recombination. In the algae, a large number of markers showed significant linkage in most plots with sufficient polymorphism.

\section{Spatial autocorrelation and isolation by distance.}

The variograms of gene diversity revealed similar patterns for the photobiont and mycobiont, with spatial autocorrelation extending up to $150 \mathrm{~m}$ in both. When recurrent MLG were accounted for in the variogram analysis, no significant spatial autocorrelation persisted in either symbiont (Fig. 2). The plateau value of gene diversity was slightly higher in the alga than in the fungus. Also, the variograms of genotype diversity indicated very similar patterns in both symbionts. Significant spatial autocorrelation extended up to $200 \mathrm{~m}$ in the fungus and the alga (Fig. 2C). When accounting for the effect of genetic distance between algal populations, the partial Mantel test of geographic distance and genetic distance among fungal populations was not significant $\left(r_{\mathrm{M}}=-0.093, P=0.932\right)$.

\section{One-to-many associations.}

In the 887 individuals included in the study, we did not find evidence of individual thalli containing multiple algal or fungal genotypes, as indicated by the presence of a single allele at each microsatellite marker per individual. However, we had deliberately excluded an additional 15 thalli that contained multiple alleles in the three-locus data (Werth et al. 2006a). These thalli containing multiple alleles were not randomly distributed across the landscape: 12 of 15 occurred within two plots and, in 12 samples, the same algal allelic combination was found, indicating that, during clonal propagation, multiple photobionts can be transmitted. However, overall, one-to many associations of symbiont genotypes appeared to be rather rare: only $0.3 \%$ of thalli 
had multiple fungi, and $1.6 \%$ of thalli included multiple photobionts (all numbers are based on three-locus data sets).

Mycobiont and photobiont diversity and genetic distance.

Information on the number of alleles at each marker and plot, as well as the number of algal and fungal MLG, is presented in Supplementary Table S2. The fungal marker LPu24 was monomorphic in our study area. The maximum number of alleles found in any of the loci was 48 (fungal marker LPu25). Nei's unbiased gene diversity was strongly and significantly correlated between mycobiont and photobiont populations ( $\rho=$ $0.796, P<0.0001)$. The mean gene diversity was somewhat higher in the photobiont $(0.357)$ than in the mycobiont populations (0.269), a difference that was significant $(t=-4.82, \mathrm{df}=$ $40, P<0.0001$; mean of the differences $=0.088)$. The partial

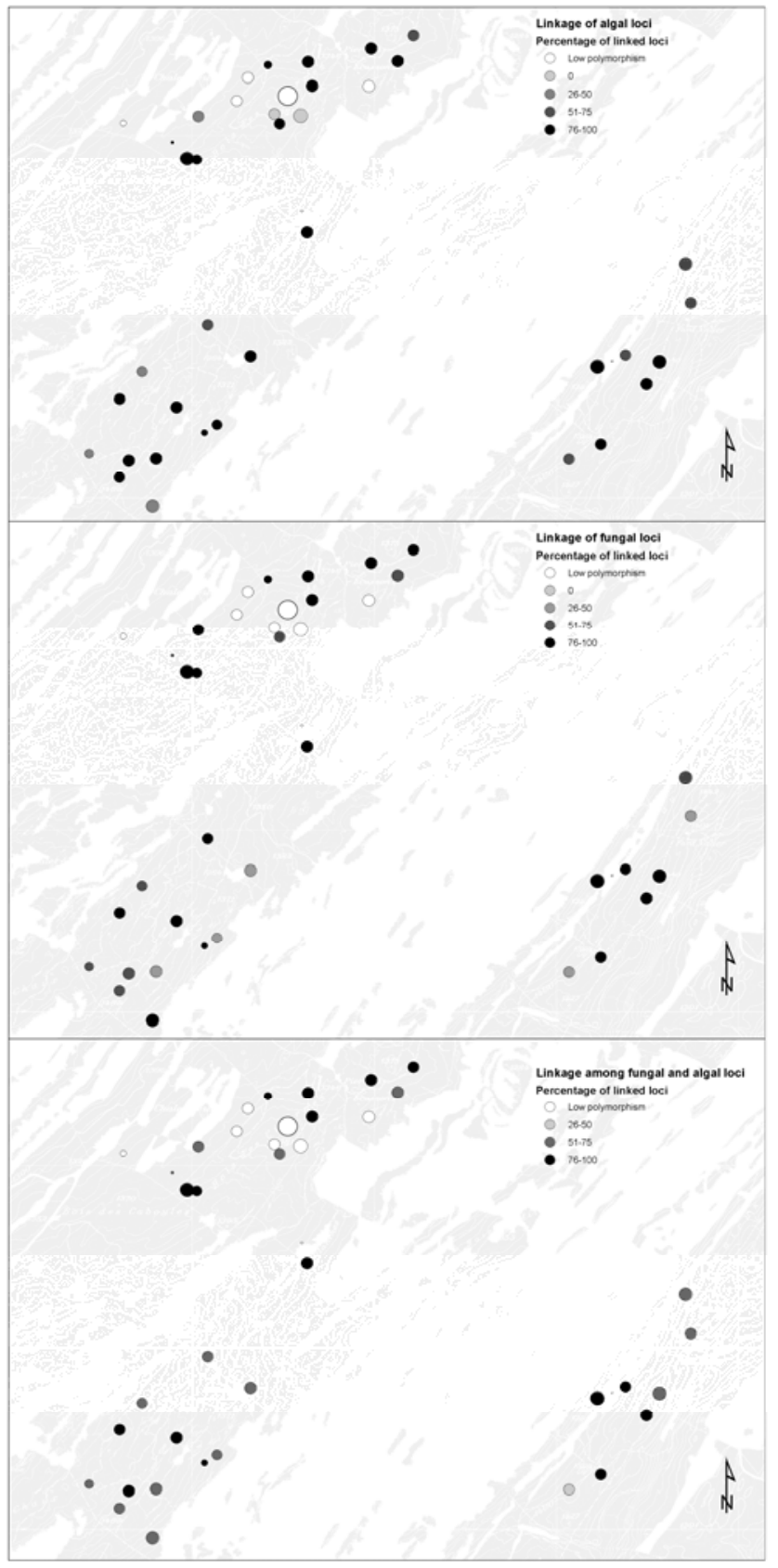

Fig. 1. Linkage disequilibrium between algal loci, between fungal loci, and between algal and fungal loci. Map shows the percentage of linked loci, with symbol size proportional to the sample size, so that plots where the results could be biased due to low sample size are printed with small symbols.
Mantel correlation between fungal and algal genetic distance matrices was highly significant when accounting for geographic distance $\left(r_{\mathrm{M}}=0.384, P<0.001\right)$.

\section{Expected frequency of recurrent MLG.}

Our dataset consisted of 139 fungal and 209 algal MLG. At the landscape level, our data deviated markedly from the expectation of MLG numbers and MLG recurrence under pan-
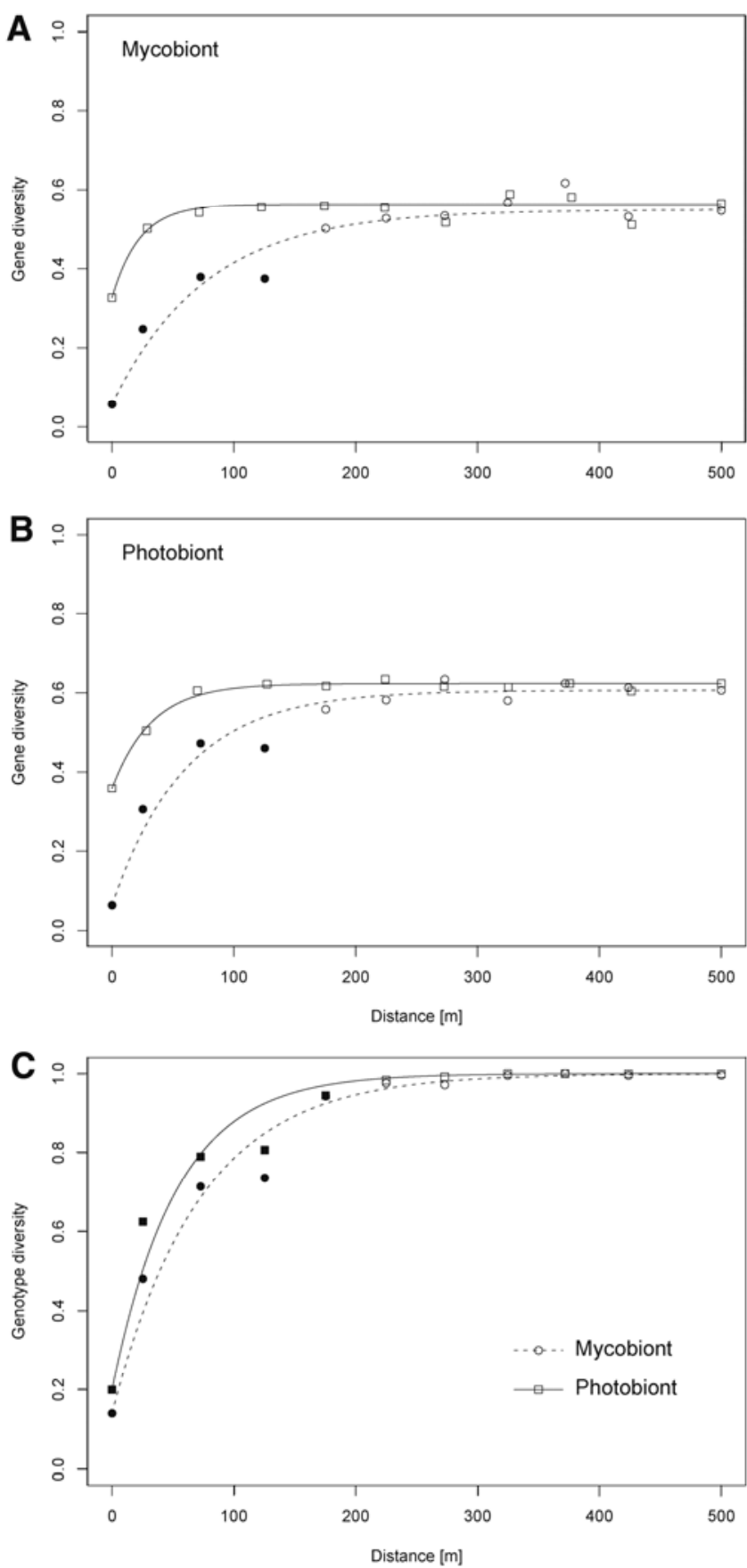

Fig. 2. Variograms for Lobaria pulmonaria and its green-algal photobiont. Each symbol shows the mean semivariance over the microsatellite loci, averaged over all pairs of thalli within each distance class. Significant positive spatial autocorrelation (solid symbols) is based on a one-sided Mantel permutation test with progressive Bonferroni correction. A, Variograms of gene diversity in the mycobiont. Semivariance is weighted for recurrent genotypes $(\mathbf{\square}, \square)$ or unweighted $(\boldsymbol{\bullet}, \mathrm{O})$. B, Variograms of gene diversity in the photobiont. Semivariance is weighted for recurrent genotypes $(\square, \square)$ or unweighted $(\boldsymbol{\bullet}, \mathrm{O})$. C, Variograms of genotype diversity: mycobiont $(\bullet, \bigcirc)$ and photobiont $(\square, \square)$ 
mixia. The average expected total number of MLG, assuming a sexual population and no linkage, was significantly higher than the observed total number for both symbiosis partners (permutation test, 1,000 permutations, $P<0.001$ ). The average expected number of fungal MLG was 732.7, whereas 139 fungal MLG were observed. For the alga, the average expected number of MLG was 880.1 but only 209 algal MLG were found in our data. The recurrence of MLG was slightly increased in the observed data in both partners relative to the expectation under sexual reproduction, a pattern that is consistent with predominantly clonal reproduction (Fig. 3A and B).

At the level of sampling plots, a similar pattern was observed (Table 2; Fig. 4; Supplementary Table S3). In six plots, only one single fungal MLG was found and, in four plots, a single algal MLG was found, implying clonality. In 27 plots $(65.9 \%)$, the observed number of fungal MLG was significantly smaller than the expectation under plot-level panmixia. In 31 plots (75.6\%), the observed number of algal MLG was significantly smaller than expected under panmixia. Taking both of the above results together, 33 plots $(80.5 \%)$ showed evidence of fungal clonality and 35 plots $(85.4 \%)$ evidence of algal clonality (Fig. 4). Plots with a clonal mode of propagation in both fungi and algae were concentrated in the eastern and southern parts of the study area. In contrast, plots where either the fungi or algae showed evidence of either sexuality or switching of photobionts during thallus establishment from clonal propagules occurred spatially aggregated in the northern part of the study area.

Mycobiont-photobiont genotype and gene pool associations.

Relative to the expectation under random association of fungal and algal MLG at the landscape level, the frequency of mycobiont MLG associating with a single algal MLG was significantly increased; consistent with vertical transmission, $69.8 \%$ of the fungal MLG associated with a single algal MLG (permutation test, $P<0.001,1,000$ permutations) (Fig. 3C). Also, the frequency of algal MLG associating with a single fungal MLG was significantly higher than expected by chance, pointing toward the importance of clonality (permutation test, $P<$ $0.001,1,000$ permutations).

At the level of sampling plots, in 4 of 19 plots with high enough polymorphism to perform the calculations, the observed number of fungal MLG associated with a single algal MLG was consistent with random association (Table 3). Interestingly, based on the observed and expected number of fungal and algal MLG, both partners were considered to be clonal in these same plots, implying photobiont switching during the establishment of lichen thalli from clonal propagules. In the remaining plots, the data were consistent with vertical transmission mode.

A number of mycobiont MLG were observed in association with several algal MLG, indicating that some horizontal transmission of the photobiont is likely to have occurred during the history of association between symbiotic partners. For example, one fungal MLG associated with 16 algal MLG, a second with 10 algal MLG, and a third with eight algal MLG (Fig. 3C; Table 4). The first and last of these were found in two adjacent plots in the southern and northern part of the study area, respectively. The fungus associating with 10 algal MLG was found in seven plots in the southern part of the study area and in two plots in the north and east, respectively. Thus, the fungal MLG associating with many algal MLG occurred spatially clustered. In contrast, the algal MLG associated with up to five fungal MLG but $90 \%$ of all algal MLG associated with a single partner.

In both the photobiont and the mycobiont, the most likely number of gene pools as determined with Bayesian analysis of population structure was $K=2$. In the majority of plots $(73.1 \%)$, Bayesian analysis of population structure showed congruent assignments of thalli to fungal and algal gene pools at the plot level (Fig. 5); at an individual level, $54.7 \%$ of the individuals showed congruent assignments to gene pools. In the southern and eastern parts of the study area, two plots each showed incongruence. In the northern part of the study area, seven plots showed incongruence in individual assignments between fungi and algae; these were spatially aggregated.

\section{DISCUSSION}

L. pulmonaria and its green-algal photobiont, D. reticulata, showed a strikingly similar genetic structure in our study landscape: The variance components in AMOVA were similar in
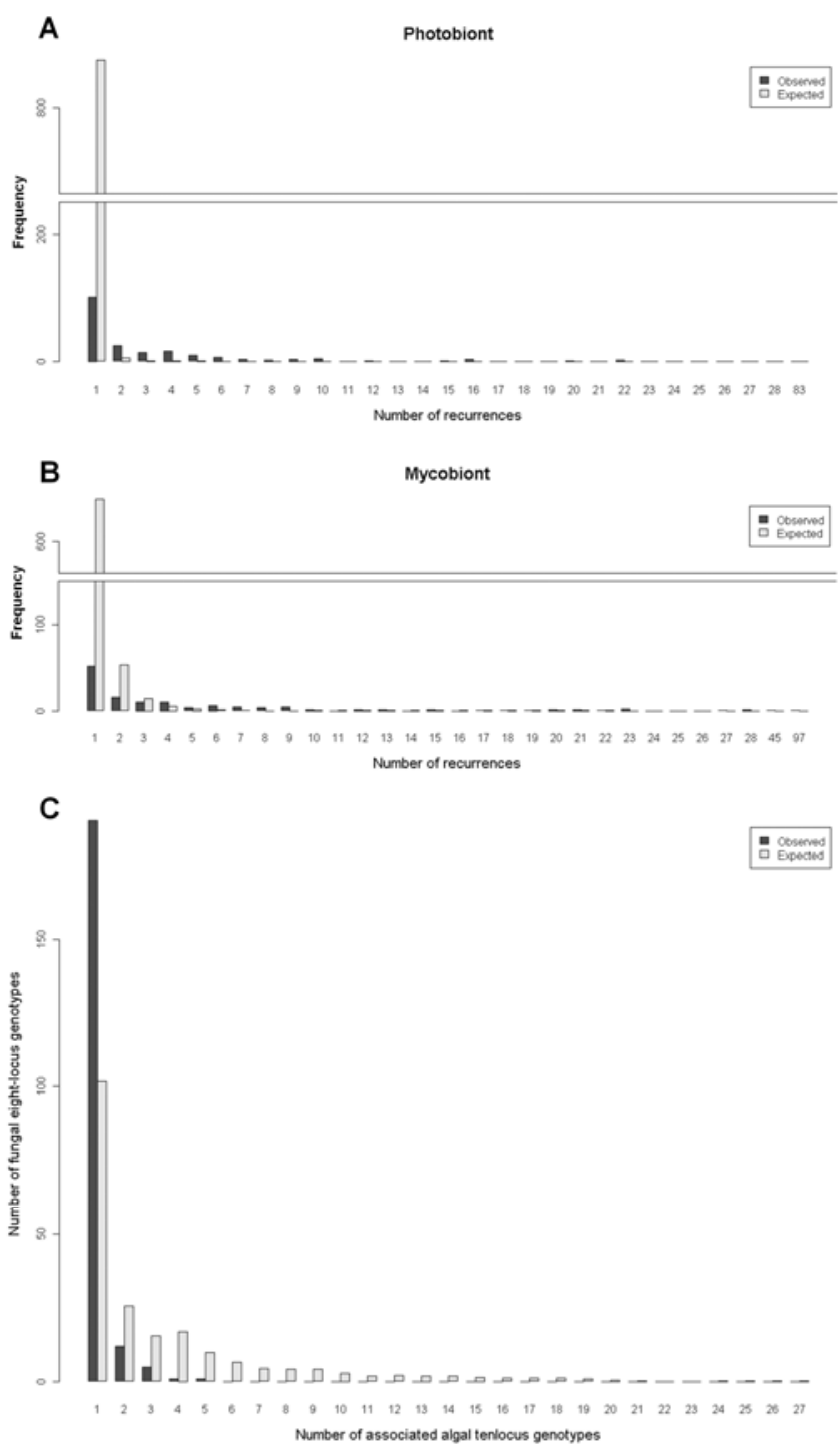

Fig. 3. Frequency of unique and recurrent multilocus genotypes based on the alleles at A, 10 algal and B, 7 fungal microsatellite markers of the epiphytic lichen Lobaria pulmonaria. Expected values were based on simulations of the expectation for a randomly mating population using the observed allele frequencies (gray bars). Observed frequencies give the number of times the observed 139 fungal and 209 algal multilocus genotypes were sampled once or recurrently (black bars). C, Frequency of the association of mycobiont multilocus genotypes with photobiont multilocus genotypes, based on the observed frequencies of fungal and algal multilocus genotypes in a sample of 887 thalli of the epiphytic lichen Lobaria pulmonaria. Expected values were based on 1,000 simulations assuming random association of photobiont and mycobiont genotypes, corresponding to horizontal transmission mode of the photobiont. Vertical transmission mode increases the frequency of mycobiont genotypes associated with one algal multilocus genotype. 
magnitude, the spatial autocorrelation structure of the data was comparable, fungal and algal genetic distance matrices were significantly correlated, and fungi and algae were assigned to the same gene pools in the majority of plots. We are unaware of any other studies that report such a high degree of correspondence between mycobiont and photobiont populations of lichens at a similar spatial scale as our study. In a recent phylogeographic study, the importance of codispersal of photobionts with mycobionts was highlighted for Cetraria aculeata, a lichen occurring in temperate and polar Northern Hemispheric as well as Antarctic habitats; this species showed a partial congruence between fungal and algal genetic structures (FernándezMendoza et al. 2011). Photobionts and mycobionts showed slightly different patterns at the range-wide scale: whereas the photobiont populations were differentiated between temperate and polar regions, the mycobiont populations were structured by climate and geography. Several previous studies have found elevated levels of population structure in photobionts, relative to their mycobionts (Piercey-Normore 2006; Werth and Sork 2010; Yahr et al. 2006). Our data showed no such tendency of the photobiont to be more structured, nor did the data on $C$. aculeata by Fernández-Mendoza and associates (2011).
Unavailability of suitable photobionts could be another reason why sexual reproduction involving photobiont switching appears to be rare in our study area. The photobiont $D$. reticulata has not been reported to form free-living populations (Dal Grande 2011). Second, attempts to demonstrate the presence of free-living populations of this species have been unsuccessful (R. Stecher and C. Scheidegger, unpublished data). Third, D. reticulata is not a frequent photobiont in Central Europe whereas it appears to be more common in southern Europe (Dal Grande 2011). Thus, for the establishment of thalli from spores, photobionts would mainly have to be recruited from dispersed soredia of conspecific individuals.

The high level of congruence of fungal and algal genetic structures in our system might also be partially due to the history of forest stands and the spatial scale of the study. For instance, stands affected by historic, stand-replacing disturbance showed elevated levels of clonality relative to forest managed by uneven-aged forestry. Second, our study was conducted within a relatively small area, within which clonality may represent an important mode of propagation. Thus, a certain degree of congruence in symbiosis partners was to be expected in our study system. The congruence in genetic structures implied that gene-

Table 2. Simulation of the number of multilocus genotypes (MLG) in plots under the assumption of panmixia at the plot level, based on 7-locus data of the fungus Lobaria pulmonaria and 10-locus data of its green-algal photobiont Dictyochloropsis reticulata ${ }^{\mathrm{a}}$

\begin{tabular}{|c|c|c|c|c|c|c|c|c|c|}
\hline \multirow[b]{2}{*}{ Plot } & \multirow[b]{2}{*}{$N$} & \multicolumn{4}{|c|}{ Algae } & \multicolumn{4}{|c|}{ Fungi } \\
\hline & & Obs.MLG & Exp.MLG & $P_{\text {Smaller }}$ & $P_{\text {Equal }}$ & Obs.MLG & Exp.MLG & $P_{\text {Smaller }}$ & $P_{\text {Equal }}$ \\
\hline W09 & 22 & 1 & 1.0 & 0 & 1 & 2 & 1.7 & 0 & 0.666 \\
\hline W13 & 23 & 11 & 23.0 & 1 & 0 & 12 & 22.2 & 1 & 0 \\
\hline W14 & 23 & 8 & 14.4 & 0.998 & 0.002 & 2 & 15.0 & 1 & 0 \\
\hline W15 & 4 & 1 & 1.0 & 0 & 1 & 1 & 1.0 & 0 & 1 \\
\hline W21 & 24 & 2 & 15.4 & 1 & 0 & 2 & 7.3 & 1 & 0 \\
\hline W32 & 22 & 4 & 12.3 & 1 & 0 & 3 & 11.2 & 1 & 0 \\
\hline W35 & 28 & 4 & 21.7 & 1 & 0 & 5 & 17.1 & 1 & 0 \\
\hline W36 & 23 & 8 & 6.7 & 0.121 & 0.172 & 1 & 1.0 & 0 & 1 \\
\hline W37 & 15 & 2 & 7.4 & 1 & 0 & 2 & 4.0 & 0.957 & 0.043 \\
\hline W40 & 24 & 11 & 24.0 & 1 & 0 & 5 & 18.8 & 1 & 0 \\
\hline W43 & 23 & 6 & 22.7 & 1 & 0 & 5 & 20.0 & 1 & 0 \\
\hline W46 & 21 & 4 & 15.3 & 1 & 0 & 4 & 9.8 & 1 & 0 \\
\hline W50 & 2 & 2 & 2.0 & 0 & 0.992 & 2 & 1.9 & 0 & 0.942 \\
\hline W51 & 24 & 6 & 23.5 & 1 & 0 & 4 & 18.7 & 1 & 0 \\
\hline W52 & 3 & 2 & 1.7 & 0 & 0.674 & 1 & 1.0 & 0 & 1 \\
\hline W55 & 10 & 1 & 1.0 & 0 & 1 & 2 & 1.7 & 0 & 0.669 \\
\hline W61 & 23 & 1 & 1.0 & 0 & 1 & 1 & 1.0 & 0 & 1 \\
\hline W64 & 28 & 7 & 23.4 & 1 & 0 & 4 & 18.0 & 1 & 0 \\
\hline W71 & 22 & 8 & 22.0 & 1 & 0 & 6 & 19.0 & 1 & 0 \\
\hline W75 & 24 & 2 & 20.2 & 1 & 0 & 2 & 17.0 & 1 & 0 \\
\hline W79 & 24 & 4 & 8.5 & 0.993 & 0.007 & 2 & 3.0 & 0.718 & 0.249 \\
\hline W82 & 24 & 10 & 23.8 & 1 & 0 & 9 & 20.3 & 1 & 0 \\
\hline W89 & 24 & 2 & 1.6 & 0 & 0.642 & 2 & 1.9 & 0 & 0.865 \\
\hline W90 & 27 & 7 & 27.0 & 1 & 0 & 11 & 21.5 & 1 & 0 \\
\hline W93 & 28 & 3 & 2.7 & 0.063 & 0.55 & 1 & 1.0 & 0 & 1 \\
\hline W96 & 26 & 12 & 25.9 & 1 & 0 & 8 & 23.5 & 1 & 0 \\
\hline W98 & 41 & 2 & 1.6 & 0 & 0.643 & 1 & 1.0 & 0 & 1 \\
\hline W103 & 12 & 2 & 4.9 & 0.974 & 0.025 & 2 & 3.6 & 0.872 & 0.113 \\
\hline W139 & 23 & 3 & 6.3 & 0.964 & 0.032 & 2 & 4.3 & 0.94 & 0.056 \\
\hline W145 & 24 & 9 & 24.0 & 1 & 0 & 8 & 20.8 & 1 & 0 \\
\hline W151 & 22 & 12 & 21.7 & 1 & 0 & 8 & 15.5 & 1 & 0 \\
\hline W185 & 26 & 20 & 25.1 & 1 & 0 & 6 & 12.0 & 0.995 & 0.005 \\
\hline W188 & 24 & 4 & 23.2 & 1 & 0 & 4 & 21.0 & 1 & 0 \\
\hline W202 & 22 & 15 & 21.9 & 1 & 0 & 14 & 21.1 & 1 & 0 \\
\hline W210 & 24 & 5 & 14.8 & 1 & 0 & 4 & 5.5 & 0.771 & 0.153 \\
\hline W221 & 22 & 8 & 19.3 & 1 & 0 & 4 & 11.5 & 1 & 0 \\
\hline W226 & 21 & 9 & 20.4 & 1 & 0 & 9 & 20.4 & 1 & 0 \\
\hline W228 & 21 & 6 & 20.7 & 1 & 0 & 5 & 15.0 & 1 & 0 \\
\hline W229 & 17 & 10 & 16.9 & 1 & 0 & 5 & 16.3 & 1 & 0 \\
\hline W230 & 24 & 7 & 23.9 & 1 & 0 & 8 & 11.1 & 0.942 & 0.042 \\
\hline W238 & 23 & 5 & 22.9 & 1 & 0 & 6 & 22.1 & 1 & 0 \\
\hline
\end{tabular}

${ }^{a} N=$ sample size; obs.MLG = observed number of fungal and algal MLG; Exp.MLG = mean expected number of MLG based on 1,000 simulation replicates; and $P_{\text {Smaller }}$ or $P_{\text {Equal }}=$ the probability that the observed number of MLG is smaller than or equal to, respectively, the expected number determined from 1,000 simulation replicates. 


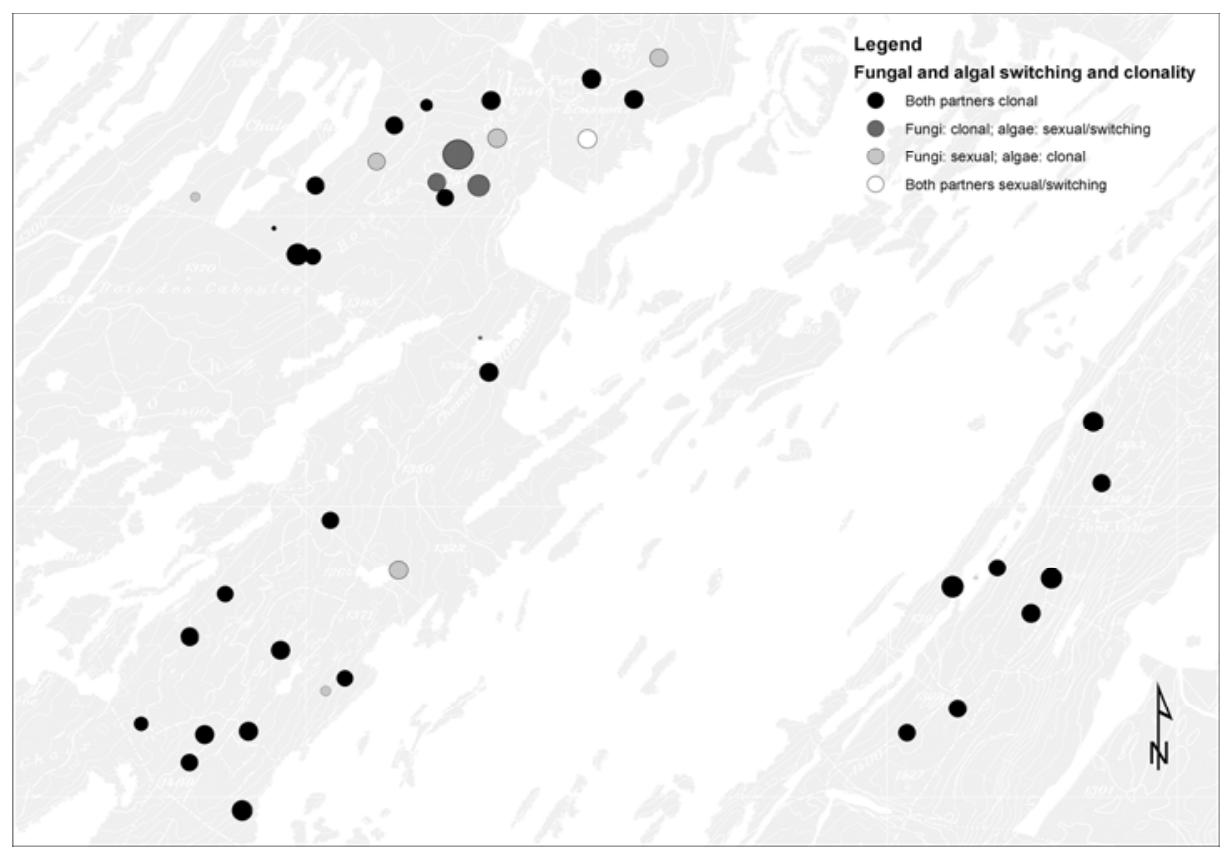

Fig. 4. Reproductive mode in plots of Lobaria pulmonaria and its green-algal photobiont Dictyochloropsis reticulata, inferred from 1,000 simulations of microsatellite data assuming panmixia within plots. Symbols are proportional to the sample size in order to downscale plots, where the results could be biased owing to low sample size.

Table 3. Plot identity, sample size $(N)$, observed number of fungal multilocus genotypes (MLG) associated with a single algal MLG (Obs. MLG.S), average expected number of fungal MLG associated with a single algal MLG (Exp. MLG.S), observed number of fungal MLG associated with multiple algal MLG (Obs.MLG.M), average expected number of fungal MLG associated with multiple algal MLG (Exp.MLG.M), probability that the observed value is smaller than the expected value $\left(P_{\mathrm{S} \text {.Smaller }}\right.$ or $\left.P_{\mathrm{M} . S m a l l e r}\right)$, and probability that the observed value is equal to the expected value $\left(P_{\text {Equal }}\right)^{\text {a }}$

\begin{tabular}{|c|c|c|c|c|c|c|c|c|}
\hline \multirow[b]{2}{*}{ Plot } & \multirow[b]{2}{*}{$N$} & \multicolumn{4}{|c|}{ Fungal MLG with a single algal MLG } & \multicolumn{3}{|c|}{ Fungal MLG with multiple algal MLG } \\
\hline & & Obs. MLG.S & Exp. MLG.S & $P_{\text {S.Smaller }}$ & $\boldsymbol{P}_{\text {Equal }}$ & Obs.MLG.M & Exp.MLG.M & $\boldsymbol{P}_{\text {M.Smaller }}$ \\
\hline W13 & 23 & 12 & 5.4 & 0 & 0 & 0 & 6.6 & 1 \\
\hline W35 & 28 & 4 & 2.2 & 0 & 0 & 1 & 2.8 & 1 \\
\hline W40 & 24 & 2 & 1.8 & 0.08 & 0.628 & 3 & 3.2 & 0.292 \\
\hline W43 & 23 & 4 & 2 & 0 & 0 & 1 & 3 & 1 \\
\hline W46 & 21 & 4 & 2.4 & 0 & 0.006 & 0 & 1.6 & 0.994 \\
\hline W71 & 22 & 4 & 2 & 0 & 0 & 2 & 4 & 1 \\
\hline W82 & 24 & 7 & 4.9 & 0.001 & 0.035 & 2 & 4.1 & 0.964 \\
\hline W90 & 27 & 10 & 6.4 & 0 & 0 & 1 & 4.6 & 1 \\
\hline W96 & 26 & 5 & 2.1 & 0 & 0 & 3 & 5.9 & 1 \\
\hline W145 & 24 & 6 & 2.5 & 0 & 0 & 2 & 5.5 & 1 \\
\hline W151 & 22 & 5 & 5.3 & 0.278 & 0.722 & 3 & 2.7 & 0 \\
\hline W185 & 26 & 0 & 0 & 0 & 0.076 & 1 & 1.9 & 0.924 \\
\hline W188 & 24 & 4 & 1 & 0 & 0 & 0 & 3 & 1 \\
\hline W202 & 22 & 13 & 11.1 & 0 & 0.006 & 1 & 2.9 & 0.994 \\
\hline W226 & 21 & 9 & 2.5 & 0 & 0 & 0 & 6.5 & 1 \\
\hline W228 & 21 & 4 & 2.1 & 0 & 0.001 & 1 & 2.9 & 0.999 \\
\hline W229 & 17 & 1 & 1.4 & 0.346 & 0.654 & 4 & 3.6 & 0 \\
\hline W230 & 24 & 6 & 4.2 & 0 & 0.005 & 2 & 3.8 & 0.995 \\
\hline W238 & 23 & 5 & 2.3 & 0 & 0 & 1 & 3.7 & 1 \\
\hline
\end{tabular}

${ }^{a}$ Probabilities and averages are based on 1,000 simulation replicates and observed frequencies of fungal and algal MLG in each plot. Plots where the hypothesis of random association between partners was not rejected are printed in bold.

Table 4. Fungal-algal multilocus genotype (MLG) associations ${ }^{\mathrm{a}}$

\begin{tabular}{|c|c|c|c|c|c|}
\hline $\begin{array}{l}\text { Number of } \\
\text { algal partners }\end{array}$ & $\begin{array}{c}\text { Number of } \\
\text { fungal MLG }\end{array}$ & $\begin{array}{c}\text { Fungal MLG } \\
(\%)\end{array}$ & $\begin{array}{c}\text { Number of } \\
\text { fungal partners }\end{array}$ & $\begin{array}{l}\text { Number of } \\
\text { algal MLG }\end{array}$ & $\begin{array}{c}\text { Algal MLG } \\
(\%)\end{array}$ \\
\hline 1 & $97 *$ & 69.8 & 1 & $190 *$ & 90.9 \\
\hline 2 & 24 & 17.3 & 2 & 12 & 5.7 \\
\hline 3 & 9 & 6.5 & 3 & 5 & 2.4 \\
\hline 4 & 2 & 1.4 & 4 & 1 & 0.5 \\
\hline 5 & 0 & 0 & 5 & 1 & 0.5 \\
\hline 6 & 4 & 2.9 & - & - & - \\
\hline 8 & 1 & 0.7 & - & - & - \\
\hline 10 & 1 & 0.7 & - & - & - \\
\hline 16 & 1 & 0.7 & - & - & - \\
\hline
\end{tabular}

${ }^{\text {a }}$ Percentages of algal and fungal MLG of Lobaria pulmonaria found in association with one or several MLG of the symbiosis partner are shown. An asterisk indicates that the observed number of MLG was significantly higher than the expectation under randomness $(P<0.001)$. 
flow patterns were symmetrical in L. pulmonaria and D. reticulata. Symmetrical gene-flow patterns have also been found in other mutualisms, e.g., in corals and vertically transmitted dinoflagellates (Bongaerts et al. 2010) and in legumes and horizontally transmitted nitrogen-fixing bacteria (Parker and Spoerke 1998). Other mutualistic taxa exhibited markedly different genetic structures, such as lichen fungi and horizontally transmitted photobionts (Piercey-Normore 2006; Werth and Sork 2010; Yahr et al. 2006), fungus-gardening ants and mainly vertically transmitted fungal cultivars and symbiotic bacteria (Mikheyev et al. 2008), squids and horizontally transmitted light-organ inhibiting-vibrios (Jones et al. 2006), and

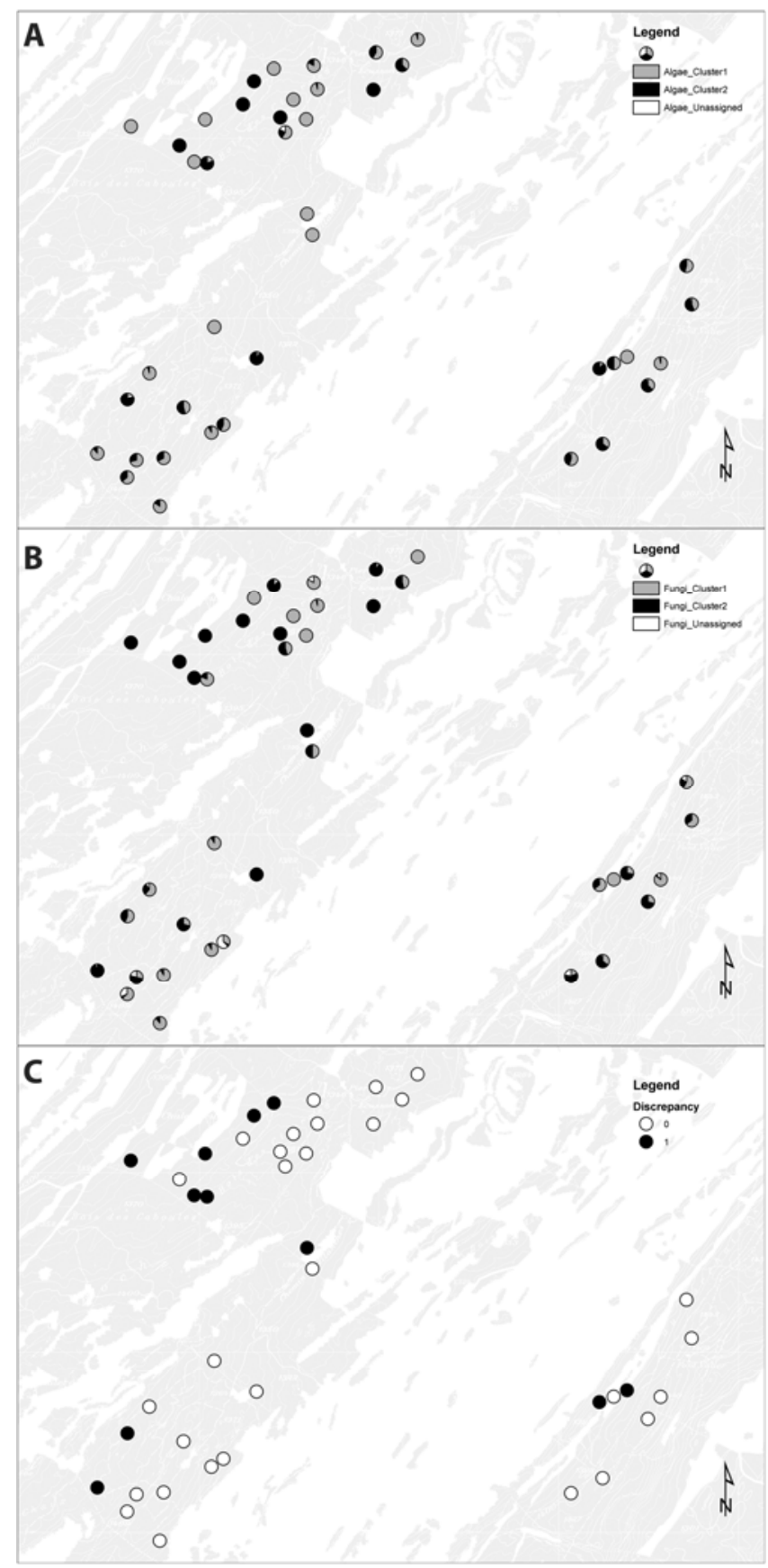

Fig. 5. Map of results from Bayesian analysis of population structure for seven microsatellite loci of Lobaria pulmonaria and 10 of its photobiont, Dictyochloropsis reticulata. A, Assignment of algae. B, Assignment of fungi to each of two clusters. C, Spatial visualization of major discrepancies in assignments. carnivorous plants and horizontally transmitted hemipteran insects (Anderson et al. 2004).

Similar patterns of gene flow in interacting species may promote local adaptation and coevolutionary processes when long time periods are considered (Anderson et al. 2004). The L. pulmonaria-D. reticulata mutualism showed significant genetic structure, corresponding to restricted gene flow at the local scale. Our study raises the question of whether the high congruence between symbiosis partners found at the small spatial scale of our study transcends into a larger-scale pattern of phylogeographic congruence in L. pulmonaria and its green-algal photobiont. Phylogeographic data and detailed analysis of single populations in continental Europe indicate that this is, indeed, the case (Dal Grande 2011; Dal Grande et al. submitted; Widmer 2009; Widmer et al. submitted). Moreover, similar to the results reported here, these authors found that, even at the large spatial scale, photobiont switches occurred rather infrequently. It is interesting that the results of genetic congruence between symbionts and infrequent photobiont switches were not only found at the small spatial scale of our study, which showed a clear signature of spatial autocorrelation at short distances, but that this same pattern also was observed in the large-scale phylogeographic study of the symbiosis.

We did not find major differences between photobiont and mycobiont spatial genetic structures (Fig. 2). This lack of difference is unlikely to be due to the number of markers. Adding markers increases marker resolution-samples that are considered as clones with fewer markers could differentiate into multiple clones if markers are added. This would lead us to expect a smaller extent of spatial autocorrelation in genotype diversity and unweighted gene diversity in the species with higher marker resolution (i.e., the photobiont) but no such difference was evident in our data.

We found a high degree of congruence in the genetic structures of the symbiosis partners. One possible scenario that might create such congruence is vertical transmission mode. For instance, vertically transmitted coral and dinoflagellate mutualists showed congruence in genetic structures (Bongaerts et al. 2010). Coral and dinoflagellate genotypes were coupled, indicating coadaptation of symbionts. The pattern observed in corals and dinoflagellate symbionts is similar to what we found in the lichen symbionts.

Congruent structures are expected even if a symbiosis is not vertically transmitted, if selection favors the incorporation of specific symbiont genotypes co-adapted to the mycobiont. Predominantly vertically transmitted mutualists showed discordant genetic structures when horizontal transmission was rare, and the partners were not co-adapted (Mikheyev et al. 2007). That we found congruent genetic structures despite evidence for horizontal transmission at both the landscape-scale analysis and the level of individual sampling plots supports the hypothesis of coadaptation (i.e., high specificity toward specific partner genotypes in the L. pulmonaria-D. reticulata mutualism). However, this does not mean that this coadaptation translates to a codiversification among fungal and algal species (Piercey-Normore and DePriest 2001).

In both partners, two spatially intermixed gene pools coexist but the mechanisms maintaining these separate gene pools are unknown. Environmental heterogeneity within plots (e.g., related to light regime or microhabitats for establishment) might potentially help to keep these separate gene pools at this small spatial scale.

We found a strong signal of clonality in the data, as evidenced by the presence of significant linkage disequilibrium between all fungal and algal loci, and significant linkage in the majority of comparisons between fungal and algal loci, at both the landscape and plot level. Also, our simulation tests pointed 
toward the importance of clonal reproduction in the lichen fungus and its photobiont. The observed number of fungal and algal MLG was significantly lower than the number expected under random mating in the landscape-scale analysis and in the majority of individual sampling plots. Together, these results imply that photobionts are predominantly codispersed in clonal propagules. However, this does not mean that the photobionts are necessarily recruited from the cells contained in an clonal propagule, because photobiont switching may occur during juvenile development (Wornik and Grube 2010). The result that fungal MLG that were associated with many photobiont MLG were geographically restricted and occurred in relatively few plots indicated such photobiont switching may, indeed, occur when L. pulmonaria thalli are recruited from clonal propagules. In many other lichen fungi, sexual reproductive mode has been reported (Arnerup et al. 2004; Högberg et al. 2002; Kroken and Taylor 2001; Werth and Sork 2008). Our finding of photobiont clonality is consistent with the concept that photobionts do not undergo sexual reproduction when in the lichen thallus (Ahmadjian 1993; Friedl and Büdel 1996; Hill 2009); thus far, only one study has reported evidence for sexual photobiont populations (Kroken and Taylor 2000).

We found a slight asymmetry in the association of fungal and algal MLG with a single partner (69.8 versus $90.9 \%$ ). This result could be an artifact of the different resolution of fungal and algal markers. The algal markers had more alleles and resolved more MLG (139 fungal versus 209 algal MLG) and, thus, in the alga, more MLG would be expected to be found in association with a single partner.

Our data do not allow concluding whether the photobiont of L. pulmonaria is vertically transmitted or, alternatively, if photobiont switches and hence, horizontal transmission mode are frequent; however, in the latter scenario, both partners would be highly coadapted at the level of MLG. In other mutualisms, ample evidence for host switches has been found; for instance, in insects and their endosymbiotic bacteria (Huigens et al. 2000; Viljakainen et al. 2008), in fungus-growing termites and fungal cultivars (Aanen et al. 2002), or in certain corals and their symbiotic dinoflagellates (Loh et al. 2001). Horizontal transmission mode has previously been reported for lichen symbioses (Piercey-Normore and DePriest 2001; Robertson and PierceyNormore 2007; Werth and Sork 2008; Wornik and Grube 2010). Photobiont switches are expected to be beneficial for the mycobiont if the local pool of photobionts is better adapted to the environmental conditions of a particular site than the photobiont strain carried along by a clonal propagule (Werth and Sork 2010; Wornik and Grube 2010). Some frequent fungal MLG occurred in association with multiple algal genotypes in our data, and discrepancies in assignments of fungi and algae to gene pools existed, both pointing toward episodes of horizontal transfer. In some cases, photobiont exchanges may occur even if a symbiosis is mainly codispersed, such as in asexual fungal species (Nelsen and Gargas 2008; Wornik and Grube 2010). It is remarkable that, in our data, despite evidence for horizontal transmission, congruent genetic structures were found in the symbionts, because a few photobiont switches would disentangle genetic structures unless fungi and algae are coadapted; in this case, only specific associations between genotypes are viable, creating associations between symbiont genotypes.

Other studies have shown the presence of multiple photobionts in lichen thalli (del Hoyo et al. 2011; Piercey-Normore 2006). One fungal species consistently associated with two species of Trebouxia photobionts (del Hoyo et al. 2011) and, in a second lichen, multiple algal genotypes frequently coexisted within a single thallus (Piercey-Normore 2006). Here, we found that such one-to-many associations are comparatively rare in L. pulmonaria $(0.3 \%$ of thalli had multiple fungi and $1.6 \%$ had multiple photobionts). The same combination of two-allelic loci occurred in multiple specimens, most of which occurred spatially aggregated in two of the plots. These results indicated that, occasionally, multiple photobiont genotypes can be co-dispersed with the fungus in the isidioid soredia of L. pulmonaria.

Our conclusions on fungal genetic structure and spatial autocorrelation patterns are consistent with those of prior studies that included a mix of photobiont and mycobiont loci, when intending to study fungal genetic structure (Wagner et al. 2005; Werth et al. 2006b, 2007). The general structure of the two AMOVA models remained the same, and the patterns of spatial autocorrelation in gene diversity and genotype diversity were very similar if the eight fungal microsatellite loci were employed, or a combination of six algal and fungal loci as in the previous articles, emphasizing the genetic similarity of the symbiosis partners.

Both L. pulmonaria and its photobiont showed spatial autocorrelation in gene diversity and genotype diversity at short spatial scales. Significant genetic structure at small spatial scales may be created if most propagules disperse and establish close to the parental genets. Thus, at short distances (e.g., within plots), genotypes are more similar to each other than expected by chance. For example, if samples collected from different trees within plots are compared, their allelic frequencies may differ due to the influence of local dispersal within trees. Owing to the influence of long-distance dispersal, at larger spatial scales, allele frequencies get homogenized (e.g., comparison between regions). Thus far, no significant spatial autocorrelation in genotypes has been found in other lichen fungi (Lättman et al. 2009; Lindblom and Ekman 2006; Werth 2010b; Werth and Sork 2008), and the spatial structure of individual photobiont species has not been reported. Here, autocorrelation analyses based on variograms showed that isolation by distance was an important force structuring populations of both fungal and algal mutualists at fine spatial scales, even though this pattern was not obvious in the partial Mantel test, likely because the plot-based distance matrices mainly contained distances larger than $150 \mathrm{~m}$ (801 of 820), distances at which little or no spatial autocorrelation remained.

Although the pattern of spatial autocorrelation in genotype diversity was similar in the symbionts, one emerging difference was that gene diversity was slightly higher in the algal than in the fungal data, consistent with the results of rarefaction analyses of a subset of fungal and algal microsatellite markers (Werth 2010a). Moreover, our result of higher diversity in the photobiont is in agreement with the pattern found in other lichen symbioses (Blaha et al. 2006; Muggia et al. 2008; Ohmura et al. 2006; Opanowicz and Grube 2004; Werth and Sork 2010).

In conclusion, the genetic structures of the mutualists L. pulmonaria and $D$. reticulata were highly similar. The pattern of association between fungal and algal loci and genotypes and the congruence in genetic structure indicated that the reproductive mode of both species was clonal, involving codispersal of the photobiont in clonal propagules. Our data were consistent with recruitment of the photobiont from codispersed cells originating from the mother thallus (i.e., vertical transmission) or with photobiont switching and the incorporation of coadapted photobionts during thallus establishment from clonal fungal propagules. The degree of coadaptation among symbionts and the extent of codispersal are important evolutionary forces that ultimately determine the large-scale genetic architecture of symbioses.

\section{MATERIALS AND METHODS}

Data sets and molecular analysis.

The study is based upon an existing dataset comprising 887 thalli of L. pulmonaria genotyped at six microsatellite loci 
(Werth et al. 2006b, 2007). Moreover, we genotyped the same samples at five additional fungal microsatellites (LPu23, LPu24, LPu25, LPu28, and MS4) (Walser et al. 2003; Widmer 2009, 2010) and seven algal microsatellites (LPh1, LPh2, LPh3, LPh4, LPh5, LPh6, and LPh7) (Dal Grande et al. 2009). Polymerase chain reaction and fragment length analyses were performed as described in Widmer (2009) for the fungal loci, and in Dal Grande and associates (2009) for the additional algal microsatellites.

\section{Study area and sampling.}

The study area was situated in a pasture-woodland landscape of the Swiss Jura Mountains. The thalli of L. pulmonaria were collected from a total of 41 plots of 1 hectare ("populations"). Of the 41 plots, 21 had been subjected to stand-replacing disturbance in the 19th century. The entire study area had been managed by uneven-aged forestry, a management practice involving the cutting of single large trees, which results in a forest containing trees of all age classes. More details about the study area are found in Kalwij and associates (2005) and Werth and associates (2006b); the sampling design is presented in Werth and associates (2006b, 2007). In short, plots were located within a maximum distance of $3.5 \mathrm{~km}$, and contained 1 to 25 trees colonized by L. pulmonaria.

\section{Statistical analysis.}

We analyzed the spatial genetic structure of $L$. pulmonaria and its primary photobiont, the green alga $D$. reticulata. To test for differences in genetic structure among symbionts, we performed hierarchical AMOVA in Arlequin version 3.11 (Excoffier et al. 2005). Two nested models were used; in the first, trees on which the lichen thalli had been sampled were nested within 1ha plots whereas, in the second, 1-ha plots were nested within two regions representing continuous forests, separated from each other by an approximately $1-\mathrm{km}$-wide pasture representing a potential barrier to gene flow.

If either of the lichen symbionts were reproducing mainly clonally, one would expect a statistically significant association of its loci. To test for an association among the fungal and algal loci, we performed tests of linkage disequilibrium in Arlequin on the entire data set. We also tested whether any of the fungal loci were significantly linked with algal loci. The latter would be the case if the photobiont were codispersed with the fungus during clonal reproduction of the fungus (i.e., vertical transmission of the photobiont) or, alternatively, if there was horizontal transfer and strong coadaptation among the partners of the symbiosis. Linkage tests were performed for both the total data set and each sampling plot alone. Because these tests can only be performed in plots with a certain level of polymorphism and a sufficiently high sample size, we excluded plots that were monomorphic or showed very low variability or very low sample size.

To assess whether there was fine-scale isolation by distance in the mycobiont and photobiont, we performed spatial autocorrelation analyses using a variogram framework, following the methods given by Wagner and associates (2005) and Werth and associates (2006b). First, we calculated variograms of gene diversity, including or downweighting recurrent fungal or algal MLG. Any discrepancy in the spatial extent of significant autocorrelation of the two analyses illustrated the relative importance of clonality in creating a spatial genetic pattern of the symbionts. Second, to infer the spatial extent of clonal genetic structure in the mycobiont and the photobiont, we calculated variograms of genotype diversity (Wagner et al. 2005). In all variogram analyses, the significance of positive spatial autocorrelation was assessed with a one-sided Mantel test applying progressive Bonferroni correction. All variogram analyses focused on fine-scale differences at the level of a few hundred meters (i.e., up to $500 \mathrm{~m}$ ).

To test whether there was large-scale isolation by distance in the mycobiont and photobiont populations, we performed partial Mantel tests (Mantel 1967) using 1,000 permutations of Euclidean geographic distance and Roger's Euclidean distance among fungal or algal populations calculated in $\mathrm{R}$ ( $\mathrm{R}$ Development Core Team, Vienna) using the function "dist.genepop" in the package adegenet (Jombart 2008). The Mantel correlation coefficient $r_{\mathrm{M}}$, calculated as Spearman's rank correlation coefficient, quantified the partial correlation between geographic and fungal genetic distance, when the effect of algal genetic distance had been removed. The partial Mantel tests was performed using the library "vegan" version 1.6.7 (function "mantel") (Dixon 2003) in R.

To test for an association of mycobiont and photobiont diversities at the plot level, Nei's unbiased gene diversity (Nei 1978) was calculated using a resampling procedure that randomly drew one thallus per tree and created 1,000 resampled datasets, as described by Werth and associates (2006b). For each plot of 1 ha, the mean gene diversity was calculated averaging over 1,000 resampled datasets. To test whether Nei's unbiased gene diversity was correlated in the photobiont and the mycobiont, we calculated the Spearman's rank correlation coefficient, $\rho$, and its significance using the function "cor.test" in R. Then, we tested whether the mean of Nei's unbiased gene diversity differed between mycobiont and photobiont using a two-sided, paired Student's $t$ test assuming unequal variances in R (function "t.test"). If the symbioses were mainly codispersed, the genetic distance matrices of the symbionts would be predicted to be correlated when accounting for the potential effect of geography. Thus, we computed the partial Mantel correlation of fungal and algal genetic distance in $\mathrm{R}$, removing the effect of geographic distance and using the same settings as in the partial Mantel test above.

In order to evaluate whether the fungal and algal microsatellite data were consistent with sexual or a mix of sexual and clonal reproduction, we performed a simulation test comparing the observed numbers of multilocus fungal and algal genotypes in our sample of 887 thalli against the expectation under random mating with complete sexual reproduction. This test also assumed no geographic barriers to gene flow, which was appropriate because our previous analyses indicated the lack of barriers in our study landscape (Werth et al. 2007). Nevertheless, we also performed the same test assuming panmixia at the plot level. Relative to sexual reproduction, clonality reduces the number of MLG in a sample and increases recurrence of MLG (i.e., the number of times that an MLG is expected to occur more than once) (Werth and Sork 2008). For each of 1,000 simulation replicates, 887 algal and fungal MLG were constructed, assuming observed allele frequencies-first, at the landscape level, and second, at the level of sampling plots-and no linkage disequilibrium (Werth and Sork 2008). Then, based on the proportion of resamples with a smaller or equal value than the observed number of fungal or algal MLG, we calculated the probability that the observed number was smaller than $\left(P_{\text {smaller }}\right)$ or equal to $\left(P_{\text {equal }}\right)$ the expectation under panmixia.

Even if the reproductive mode of both symbiosis partners were clonal, it could still be that photobionts are regularly exchanged when lichen thalli are recruited from clonal propagules. Whereas horizontal transmission shuffles fungal and algal MLG, vertical transmission increases the frequency of mycobiont MLG associated with only one photobiont genotype, as well as the frequency of photobiont MLG associated with a single mycobiont MLG. To test whether the fungal-algal association deviated from randomness as expected under horizontal trans- 
mission, we performed a second simulation test comparing the observed frequencies of fungal eight-locus genotypes found among 887 thalli of L. pulmonaria in association with one or multiple algal MLG with the frequency of the association expected under randomness, based on the same sample size. First, for each of 1,000 simulation replicates, the algal MLG were shuffled with replacement in R keeping the fungal MLG constant, and assuming observed frequencies of fungal and algal MLG. Second, for 1,000 replicates, we shuffled the fungal MLG with replacement while keeping the algal MLG constant. To assess whether the frequency of genotype associations was consistent with horizontal transfer, we calculated the proportion of simulation replicates where the observed number of algae and fungi associated with a single MLG of their partner was significantly higher than the expectation under randomness. We performed this analysis on the total dataset (assuming that photobiont switching is possible among partners dispersed among different plots) as well as at the plot level. For the plot-level analysis, we excluded plots that contained fewer than five MLG in either of the symbiosis partners, as in low-diversity plots, only few links between the partners are possible. Moreover, here we distinguished between the number of fungal MLG that were associated with a single algal MLG and those associated with multiple algal MLG. We calculated the probability that the observed number of fungal MLG associated with a single algal MLG was smaller $\left(P_{\text {S.Smaller }}\right)$ than or equal to $\left(P_{\text {equal }}\right)$ the expectation under random association (i.e., shuffling algal MLG within plots). The probability $\left(P_{\mathrm{M} . \text { Smaller }}\right)$ that the observed number of fungal MLG associated with multiple algal MLG was smaller than the expectation under random association was $1-\left(P_{\text {S.Smaller }}+P_{\text {equal }}\right)$.

Bayesian analyses of population structure were performed in order to test whether fungi and algae were consistently assigned to the same gene pools, as expected under vertical transmission mode. Bayesian analysis of population structure assigns individual MLG to a predefined number $(K)$ of panmictic populations. We ran the program Structure version 2.3.3 (Pritchard et al. 2000) using correlated allele frequencies (Falush et al. 2003) for 10 replicate runs for each $K \in\{1, \ldots, 10\}$, using 10,000 iterations as burn-in followed by 100,000 iterations during which the posterior distribution of parameters was sampled. Plots of $\alpha$ and $F_{\mathrm{ST}}$ were inspected visually to ensure that runs had reached convergence after the burn-in period. We utilized an admixture model, which estimated the fraction of ancestry of each individual in each gene pool. A uniform prior on admixture, $\alpha$, was assumed for all gene pools. Individuals with $\geq 80 \%$ probability of ancestry in a particular gene pool were treated as assigned to that gene pool, whereas individuals with $<80 \%$ probability of ancestry in any gene pool were considered to be "unassigned". The number of gene pools was inferred using the method by Evanno and associates (2005). Briefly, the statistic $\Delta K$ is based on the rate of change in log likelihoods of the data between successive values of $K$. The most likely number of gene pools is the mode of the distribution of $\Delta K$ over $K$ (Evanno et al. 2005).

\section{ACKNOWLEDGMENTS}

We thank D. Scofield, F. Dal Grande, and I. Widmer for valuable discussions. This project was funded by the Swiss National Science Foundation (fellowship PBBEA-111207 to S. Werth and grant 3100AO-105830 and 31003A_1276346/1 to C. Scheidegger).

\section{LITERATURE CITED}

Aanen, D. K., Eggleton, P., Rouland-Lefevre, C., Guldberg-Froslev, T., Rosendahl, S., and Boomsma, J. J. 2002. The evolution of fungus-growing termites and their mutualistic fungal symbionts. Proc. Natl. Acad.
Sci. U.S.A. 99:14887-14892.

Ahmadjian, V. 1993. The Lichen Symbiosis. John Wiley and Sons, New York.

Anderson, B., Olivieri, I., Lourmas, M., and Stewart, B. A. 2004. Comparative population genetic structures and local adaptation of two mutualists. Evolution 58:1730-1747.

Arnerup, J., Högberg, N., and Thor, G. 2004. Phylogenetic analysis of multiple loci reveal the population structure within Letharia in the Caucasus and Morocco. Mycol. Res. 108:311-316.

Beck, A., Friedl, T., and Rambold, G. 1998. Selectivity of photobiont choice in a defined lichen community: Inferences from cultural and molecular studies. New Phytol. 139:709-720.

Beck, A., Kasalicky, T., and Rambold, G. 2002. Myco-photobiontal selection in a Mediterranean cryptogam community with Fulgensia fulgida. New Phytol. 153:317-326.

Blaha, J., Baloch, E., and Grube, M. 2006. High photobiont diversity associated with the euryoecious lichen-forming ascomycete Lecanora rupicola (Lecanoraceae, Ascomycota). Biol. J. Linn. Soc. 88:283-293.

Bongaerts, P., Riginos, C., Ridgway, T., Sampayo, E. M., van Oppen, M. J. H., Englebert, N., Vermeulen, F., and Hoegh-Guldberg, O. 2010. Genetic divergence across habitats in the widespread coral Seriatopora hystrix and its associated Symbiodinium. PLoS One 5.

Büdel, B., and Scheidegger, C. 2008. Thallus morphology and anatomy. Pages 40-68 in: Lichen Biology. T. H. Nash, ed. Cambridge University Press, Cambridge.

Dal Grande, F. 2011. Phylogeny and co-phylogeography of a photobiontmediated guild in the lichen family Lobariaceae. Ph.D. thesis. Philosophisch-naturwissenschaftliche Fakultät. University of Berne, Berne, Switzerland.

Dal Grande, F., Widmer, I., Beck, A., and Scheidegger, C. 2009. Microsatellite markers for Dictyochloropsis reticulata (Trebouxiophyceae), the symbiotic alga of the lichen Lobaria pulmonaria (L.). Conserv. Genet. 1-3. Published online.

Dal Grande, F., Widmer, I., Wagner, H. H., and Scheidegger, C. Vertical and horizontal photobiont transmission within populations of a lichen symbiosis. Submitted.

del Hoyo, A., Álvarez, R., del Campo, E. M., Gasulla, F., Barreno, E., and Casano, L. M. 2011. Oxidative stress induces distinct physiological responses in the two Trebouxia phycobionts of the lichen Ramalina farinacea. Ann. Bot. 107:1-10.

Dixon, P. 2003. Vegan, a package of R functions for community ecology. J. Veg. Sci. 14:927-930.

Evanno, G., Regnaut, S., and Goudet, J. 2005. Detecting the number of clusters of individuals using the software STRUCTURE: A simulation study. Mol. Ecol. 14:2611-2620.

Excoffier, L., Laval, G., and Schneider, S. 2005. Arlequin ver. 3.0: An integrated software package for population genetics data analysis. Evol. Bioinf. 1:47-50. Published online.

Falush, D., Stephens, M., and Pritchard, J. 2003. Inference of population structure using multilocus genotype data: Linked loci and correlated allele frequencies. Genetics 164:1567-1587.

Fernández-Mendoza, F., Domaschke, S., García, M. A., Jordan, P., Martín, M. P., and Printzen, C. 2011. Population structure of mycobionts and photobionts of the widespread lichen Cetraria aculeata. Mol. Ecol. 20:1208-1232.

Friedl, T., and Büdel, B. 1996. Photobionts. Pages 8-23 in: Lichen Biology. T. H. Nash, ed. Cambridge University Press, Cambridge.

Hill, D. J. 2009. Asymmetric coevolution in the lichen symbiosis caused by a limited capacity for adaptation in the photobiont. Bot. Rev. 75:326338.

Högberg, N., Kroken, S., Thor, G., and Taylor, J. W. 2002. Reproductive mode and genetic variation suggest a North American origin of European Letharia vulpina. Mol. Ecol. 11:1191-1196.

Huigens, M. E., Luck, R. F., Klaassen, R. H. G., Maas, M., Timmermans, M., and Stouthamer, R. 2000. Infectious parthenogenesis. Nature 405:178-179

Jombart, T. 2008. adegenet: A R package for the multivariate analysis of genetic markers. Bioinformatics 24:1403-1405.

Jones, B. W., Lopez, J. E.. Huttenburg, J., and Nishiguchi, M. K. 2006. Population structure between environmentally transmitted vibrios and bobtail squids using nested clade analysis. Mol. Ecol. 15:4317-4329.

Kalwij, J. M., Wagner, H. H., and Scheidegger, C. 2005. Effects of standlevel disturbances on the spatial distribution of a lichen indicator. Ecol. Appl. 15:2015-2024.

Kroken, S., and Taylor, J. W. 2000. Phylogenetic species, reproductive mode, and specificity of the green alga Trebouxia forming lichens with the fungal genus Letharia. Bryologist 103:645-660.

Kroken, S., and Taylor, J. W. 2001. Outcrossing and recombination in the lichenized fungus Letharia. Fungal Genet. Biol. 34:83-92.

Lättman, H., Lindblom, L., Mattsson, J. E., Milberg, P., Skage, M., and 
Ekman, S. 2009. Estimating the dispersal capacity of the rare lichen Cliostomum corrugatum. Biol. Conserv. 142:1870-1878.

Lindblom, L., and Ekman, S. 2006. Genetic variation and population differentiation in the lichen-forming ascomycete Xanthoria parietina on the island Storfosna, central Norway. Mol. Ecol. 15:1545-1559.

Loh, W. K. W., Loi, T., Carter, D., and Hoegh-Guldberg, O. 2001. Genetic variability of the symbiotic dinoflagellates from the wide ranging coral species Seriatopora hystrix and Acropora longicyathus in the Indo-West Pacific. Mar. Ecol. Prog. Ser. 222:97-107.

Mantel, N. 1967. The detection of disease clustering and a generalized regression approach. Cancer Res. 27:209-220.

Mikheyev, A. S., Mueller, U. G., and Boomsma, J. J. 2007. Population genetic signatures of diffuse co-evolution between leaf-cutting ants and their cultivar fungi. Mol. Ecol. 16:209-216

Mikheyev, A. S., Vo, T., and Mueller, U. G. 2008. Phylogeography of postPleistocene population expansion in a fungus-gardening ant and its microbial mutualists. Mol. Ecol. 17:4480-4488.

Muggia, L., Grube, M., and Tretiach, M. 2008. Genetic diversity and photobiont associations in selected taxa of the Tephromela atra group (Lecanorales, lichenised Ascomycota). Mycol. Prog. 7:147-160.

Mulvey, M., Aho, J. M., Lydeard, C., Leberg, P. L., and Smith, M. H. 1991. Comparative population genetic structure of a parasite (Fascioloides magna) and its definitive host. Evolution 45:1628-1640.

Nei, M. 1978. Estimation of average heterozygosity and genetic distance from a small number of individuals. Genetics 89:583-590.

Nelsen, M. P., and Gargas, A. 2008. Dissociation and horizontal transmission of codispersing lichen symbionts in the genus Lepraria (Lecanorales: Stereocaulaceae). New Phytol. 177:264-275.

Ohmura, Y., Kawachi, M., Kasai, F., Watanabe, M. M., and Takeshita, S. 2006. Genetic combinations of symbionts in a vegetatively reproducing lichen, Parmotrema tinctorum, based on ITS rDNA sequences. Bryologist 109:43-59.

Opanowicz, M., and Grube, M. 2004. Photobiont genetic variation in Flavocetraria nivalis from Poland (Parmeliaceae, lichenized Ascomycota). Lichenologist 36:125-131.

Parker, M. A., and Spoerke, J. M. 1998. Geographic structure of lineage associations in a plant-bacterial mutualism. J. Evol. Biol. 11:549-562.

Piercey-Normore, M. D. 2006. The lichen-forming ascomycete Evernia mesomorpha associates with multiple genotypes of Trebouxia jamesii. New Phytol. 169:331-344.

Piercey-Normore, M. D. 2009. Vegetatively reproducing fungi in three genera of the Parmeliaceae share divergent algal partners. Bryologist 112:773-785.

Piercey-Normore, M. D., and DePriest, P. T. 2001. Algal switching among lichen symbioses. Am. J. Bot. 88:1490-1498.

Pritchard, J., Stephens, M., and Donnelly, P. 2000. Inference of population structure using multilocus genotype data. Genetics 155:945-959.

Rambold, G., Friedl, T., and Beck, A. 1998. Photobionts in lichens: Possible indicators of phylogenetic relationships? Bryologist 101:392-397.

Robertson, J., and Piercey-Normore, M. D. 2007. Gene flow in symbionts of Cladonia arbuscula. Lichenologist 39:69-82.

Scheidegger, C., and Werth, S. 2009. Conservation strategies for lichens: Insights from population biology. Fungal Biol. Rev. 23:55-66.

Sullivan, T. J., and Faeth, S. H. 2004. Gene flow in the endophyte Neotyphodium and implications for coevolution with Festuca arizonica. Mol. Ecol. 13:649-656.
Tschermak-Woess, E. 1995. Dictyochloropsis splendida (Chlorophyta), the correct phycobiont of Phlyctis argena and the high degree of selectivity or specificity involved. Lichenologist 27:169-187.

Viljakainen, L., Reuter, M., and Pamilo, P. 2008. Wolbachia transmission dynamics in Formica wood ants. BMC Evol. Biol. 8:55.

Wade, M. J. 2003. Community genetics and species interactions. Ecology 84:583-585.

Wade, M. J. 2007. The co-evolutionary genetics of ecological communities. Nat. Rev. Genet. 8:185-195.

Wagner, H. H., Holderegger, R., Werth, S., Gugerli, F., Hoebee, S. E., and Scheidegger, C. 2005. Variogram analysis of the spatial genetic structure of continuous populations using multilocus microsatellite data. Genetics 169:1739-1752.

Walser, J. C., Sperisen, C., Soliva, M., and Scheidegger, C. 2003. Fungusspecific microsatellite primers of lichens: Application for the assessment of genetic variation on different spatial scales in Lobaria pulmonaria. Fungal Genet. Biol. 40:72-82.

Werth, S. 2010a. Optimal sample sizes and allelic diversity in studies of the genetic variability of mycobiont and photobiont populations. Lichenologist 43:1-9.

Werth, S. 2010b. Population genetics of lichen-forming fungi-A review. Lichenologist 42:499-519.

Werth, S., and Sork, V. L. 2008. Local genetic structure in a North American epiphytic lichen, Ramalina menziesii (Ramalinaceae). Am. J. Bot. 95:568-576.

Werth, S., and Sork, V. L. 2010. Identity and genetic structure of the photobiont of the epiphytic lichen Ramalina menziesii on three oak species in southern California. Am. J. Bot. 97:821-830

Werth, S., Wagner, H. H., Gugerli, F., Holderegger, R., Csencsics, D., Kalwij, J. M., and Scheidegger, C. 2006a. Quantifying dispersal and establishment limitation in a population of an epiphytic lichen. Ecology 87:2037-2046.

Werth, S., Wagner, H. H., Holderegger, R., Kalwij, J. M., and Scheidegger, C. 2006b. Effect of disturbances on the genetic diversity of an old-forest associated lichen. Mol. Ecol. 15:911-921.

Werth, S., Gugerli, F., Holderegger, R., Wagner, H. H., Csencsics, D., and Scheidegger, C. 2007. Landscape-level gene flow in Lobaria pulmonaria, an epiphytic lichen. Mol. Ecol. 16:2807-2815.

Widmer, I. 2009. Evolutionary History and Phylogeography of a Lichen Symbiosis. Ph.D. thesis. Faculty of Philosophy and Natural Sciences, University of Berne, Berne, Switzerland.

Widmer, I., Dal Grande, F., Cornejo, C., and Scheidegger. C. 2010. Highly variable microsatellite markers for the fungal and algal symbionts of the lichen Lobaria pulmonaria and challenges in developing biont-specific molecular markers for fungal associations. Fungal Biol. 114:538-544.

Widmer, I., Dal Grande, F., Excoffier, L., Holderegger, R., Keller, C., Mikryukov, V., and Scheidegger, C. Phylogeography of a lichen symbiosis. Submitted.

Wornik, S., and Grube, M. 2010. Joint dispersal does not imply maintenance of partnerships in lichen symbioses. Microb. Ecol. 59:150-157.

Yahr, R., Vilgalys, R., and DePriest, P. T. 2004. Strong fungal specificity and selectivity for algal symbionts in Florida scrub Cladonia lichens. Mol. Ecol. 13:3367-3378.

Yahr, R., Vilgalys, R., and DePriest, P. T. 2006. Geographic variation in algal partners of Cladonia subtenuis (Cladoniaceae) highlights the dynamic nature of a lichen symbiosis. New Phytol. 171:847-860. 